\title{
Modelo de gestión cultural: Una experiencia con el Qhapaq Ñan en Huánuco
}

\author{
Cultural management model: \\ An experience with Qhapaq Ñan in Huánuco
}

Denesy Palacios Jiménez

Universidad Nacional Hermilio Valdizán

\section{RESUMEN}

Objetivos: Plantear el aprovechamiento del patrimonio cultural arqueológico del Qhapaq Nan en Huánuco en condición de parque cultural, mediante un modelo eficiente de gestión cultural basada en la investigación, protección, conservación y uso social, para convertir a este lugar en un destino turístico y así contribuir con un proyecto no solo para salvaguardarlo sino también para incrementar los ingresos económicos y reducir los niveles de pobreza en la zona. Métodos: Se trata de un estudio que describe y recoge experiencias de gestión cultural respecto a cómo se aprovecha en otros sitios el legado o patrimonio cultural arqueológico, tanto en el ámbito mundial como nacional. La investigación fue cuantitativa y cualitativa, con un alcance correlacional. Se usó el diseño descriptivo, comparativo, analítico, histórico, deductivo. Resultados: El estudio plantea la necesidad de optimizar los recursos para el aprovechamiento del Qhapaq N̄an como parque cultural a través de una adecuada gestión cultural, y que dicho parque comprenderá $68,34 \mathrm{~km}$, desde el tambo de Tambococha o Tunsucancha hasta el tambo de Taparako, por ser uno de los tramos mejor conservados e involucra importantes zonas de patrimonio cultural material e inmaterial. Conclusiones: El Camino Inca en Huánuco es uno de los patrimonios más importantes del país, y es posible ser impulsado como un parque cultural mediante un modelo de gestión cultural, si tenemos en cuenta las diversas experiencias de gestión en el país y en mundo, cuyos aportes deben servir de apoyo para un modelo de gestión en este campo.

Palabras clave: Gestión cultural, patrimonio arqueológico, parque cultural, destino turístico, Qhapaq Nan.

1 Magíster y licenciada en Arqueología, doctora en Turismo. Docente principal de la Facultad de Ciencias Sociales de la Universidad Nacional Hermilio Valdizán de Huánuco. 


\section{ABSTRACT}

Objectives: To advise the right usage of archaeological cultural heritage from Qhapaq Ñan in Huánuco as a cultural park, through a cultural management efficient model based on research, protection, conservation and social use, to turn this place into a touristic destination and so contribute to a project not only to safeguard this heritage but also to increase income and reduce poverty levels in the area. Methods: This is a comparative study that describes and to gather the cultural management experiences about how people in other places take advantage of the legacy and archaeological cultural heritage, both nationally and globally. The design model was correlational. The research was quantitative and qualitative. Descriptive, comparative, analytical, historical, deductive methods were used. Results: The study suggests the need to optimize resources to take advantage of Qhapaq Ñan as a cultural park through an adequate cultural management, the park will comprise 68,34 $\mathrm{km}$ from the Tambococha or Tunsucancha Tambo to Taparako Tambo, because it is one of the best preserved sectors and involves important areas of tangible and intangible cultural heritage. Conclusions: The Inca Road in Huanuco is one of the most important heritages in the region and the country, and that it is possible to be promoted as a cultural park using a cultural management model, if we take into account the various management experiences in the country and in the world.

Keywords: Cultural management, archaeological heritage, cultural park, touristic destination, Qhapaq Ñan.

\section{INTRODUCCIÓN}

El Perú es un destino turístico reconocido por su legado cultural e histórico, cualidad que nos da una indudable ventaja que debemos aprovechar para incrementar los ingresos económicos en el país y reducir los niveles de pobreza.

Entre las enormes posibilidades turísticas que ofrece nuestro patrimonio cultural, tanto material como inmaterial, el impresionante Camino Inca, conocido como Qhapaq Nan, sobresale como una de las mejores ofertas turísticas.

El Qhapaq Ñan es la gran red vial incaica construida durante el Tahuantinsuyo en el país y que hoy alcanza hasta los países que conformaron el Imperio Incaico como Colombia, Ecuador, Bolivia, Chile, Argentina. Es el sistema vial andino más antiguo de América y el sistema comunicación más impresionante creado por nuestros antepasados, por lo que en junio de este año ha sido reconocido como Patrimonio Mundial de la Humanidad por la Unesco.

Por su trascendencia cultural y su potencialidad económica, en el 2001 el Gobierno peruano, mediante Decreto Supremo $N^{\circ}$ 031-2001-ED, lo declaró de preferente interés nacional para la investigación, registro, protección, conservación y puesta en valor; conformó para el impulso de estas acciones una Comisión Nacional, con la participación de diversas instituciones del Estado; y designó al Instituto Nacional de Cultura, hoy Ministerio de la Cultura, como ejecutor del denominado Proyecto Qhapaq Ñan.

El Camino Inca que abarcó su mayor recorrido en nuestro país y que integró todo el Tahuantinsuyo por la cordillera de los Andes, tuvo como uno de sus tramos más importantes a la zona que hoy constituye la región Huánuco, conocida en la época como Huánuco Viejo o Huánuco Pampa y que fue considerada como la capital del Chinchaysuyo, una de las cuatro regiones políticas del Imperio.

Este gran tramo, que muestra su mayor evidencia arqueológica precisamente en Huánuco Pampa, zona ubicada en el distrito de La Unión, provincia de Dos Mayo, comprende además una serie de lugares en el todo el departamento y región Huánuco con diversos atractivos que deben ser aprovechados mediante una apropiada gestión cultural y turística. 
El presente estudio, por esta razón, plantea un modelo de gestión cultural de calidad para poner en valor el Qhapaq Ñan en la región Huánuco y convertirlo en un atractivo destino turístico de cultura material e inmaterial, mediante acciones de revaloración, conservación, protección, investigación y aprovechamiento en condición de parques culturales, esfuerzos que en dicho legado por cierto hoy no existen y cada vez más este luce en abandono y deterioro causado por la acción de los habitantes y las inclemencias del tiempo.

El tramo que el estudio pretende impulsar abarca el Camino Inca desde el tambo de Tunsucancha (Chinchaycocha) hasta el tambo Taparaco. El trabajo está centralizado en Huánuco, por razones de conservación y buen estado en que se encuentra el referido tramo, y su relación con sitios monumentales muy importantes como los Baños del Inca, la ciudad preinca de Huánuco Pampa y otros atractivos próximos a esta red vial incaica, además de incorporar el bello paisaje y la cultura de las poblaciones adyacentes que guardan y suelen proyectar la riqueza de sus costumbres ancestrales.

La investigación se inspira en la experiencia de otros países, que apuestan por la implementación de una amplia oferta de turismo cultural -cuya demanda crece inversamente proporcional al interés por las vacaciones de playa- y que carecen de recursos que sí encontramos, y de manera muy generosa, en nuestro país y especialmente en Huánuco. Estos países han organizado rutas culturales atractivas basadas solo en grandes dosis de creatividad y recursos económicos. Por ejemplo, los han realizado en función de personajes famosos, como la Ruta de Mozart o el Tren de la Poesía de Neruda; de temas históricos estratégicos, como la Ruta de la Seda o el Camino de Santiago de Campostela; y de manifestaciones culturales contemporáneas, como festivales de artes escénicas o música electrónica, cursos de idiomas o de cocina. Todos estos países, a través de estrategias diversas, han atraído importantes flujos turísticos en determinadas épocas del año que antes se consideraban poco activas $(1,2)$.

Otra motivación fundamental para realizar este trabajo es el gran legado arqueológico que tiene Huánuco. Esta región cuenta con una trayectoria histórica que se remonta desde Lauricocha, hacia la época incaica, como lo testimonian sus numerosos sitios arqueológicos y de arte rupestre, que son unos santuarios llenos de significado. Y además, por una razón personal y profesional, por la oportunidad que tuve de trabajar entre los años 2004 y 2005 como supervisora de Qhapaq Ñan en Huánuco, y en cuya experiencia pude constatar lo atractivo y rescatable que resulta el tramo inca que ingresa por Yanahuanca hasta el tambo Taparaco, por lo que considero que se le debe dar una función social, y qué mejor que hacerlo a través de un parque cultural, donde se manifiesten los diversos elementos, contextos y actores.

\section{MATERIAL Y MÉTODOS}

Metodológicamente, hemos hecho un trabajo comparativo, de cómo se aprovecha en otros sitios el legado o patrimonio cultural arqueológico, tanto en el ámbito mundial como nacional, y el patrimonio con el cual contamos en Huánuco, y de estas experiencias hemos extraído la fundamentación que requerimos para el parque cultural que postulamos debe hacerse en el tramo del Qhapaq Ñan de Huánuco.

El modelo de diseño es correlacional, y usamos inclusive el escalamiento de Likert para medir las actitudes y predisposición de los usuarios y operadores y de la población beneficiaria directa e indirectamente. La investigación fue cuantitativa y cualitativa. Los métodos fueron el descriptivo, el analítico, el histórico, el deductivo y el estadístico. Fundamentalmente, por la naturaleza del tema, usamos el método cualitativo, mediante entrevistas a profundidad a personas ligadas al quehacer del patrimonio cultural arqueológico, que fue complementado con el uso de métodos cuantitativos (estadístico). En el 
procedimiento se utilizó trabajo de campo, trabajo de gabinete, porque consideramos que es la metodología acorde con la realidad y su problemática.

En el ámbito mundial, no faltan experiencias de definición y diseño de parques culturales. Hay parques con arte rupestre y otros vestigios arqueológicos e históricos. Son variados tanto desde el punto de vista geográfico como histórico. Hemos elegido algunos de ellos para construir nuestra propia visión y definición de parque cultural, expresión central en nuestra investigación.

Este término es tomado de los parques naturales para proteger áreas naturales, y en muchos de ellos tenemos la existencia de legado arqueológico, que queremos darle la misma dimensión de protección y defensa, para ser vistos como una unidad.

Un caso que puede servir como ejemplo para diseñar el modelo de gestión cultural, es el Parque Nacional Natural Tayrona, ubicado en la Región Caribe en Colombia, en el Municipio de Santa Marta del departamento de Magdalena. Está a 34 km de la ciudad de Santa Marta y es uno de los parques naturales más importantes de Colombia. Aunque es una reserva natural, el parque acondiciona servicios para la práctica del ecoturismo. Numerosos espectáculos naturales y caminatas se pueden encontrar en diferentes áreas del parque. Entre estas áreas destacan el Museo Arqueológico de Chairama, que cuenta con una exposición arqueológica permanente; el Pueblito Chairama, donde existe ruinas arqueológicas de pobladores Tayrona que lo habitaron hace más de 500 años (3).

Cuenta aproximadamente con 24 mil visitantes al año, por lo que puede observarse que es un sitio medianamente frecuentado, y no solo por sus recursos naturales y bellos paisajes, sino también por los recursos culturales y arqueológicos, que nos puede servir de referente, aunque en este caso prioricen los recursos naturales. En el caso nuestro, proponemos dar prioridad al patrimonio cultural y aprovechar también el contexto natural y paisajístico, así como el turismo vivencial.

Otro ejemplo importante es el Parque Cultural de Muñopepe de arte rupestre. Está ubicado en la provincia de Ávila, en Castilla y León, importante comunidad autónoma de España, reconocida como comunidad histórica y cultural. Tiene una superficie de $6,02 \mathrm{~km}^{2}$, con una población de 108 habitantes y una densidad de 17,94 $\mathrm{hab} / \mathrm{km}^{2}$.

Cuenta con afloramientos al aire libre, repartidas en las estaciones de La Atalaya y Peña del Cuervo, donde encontramos figuras antropomorfas de tipo esquemático pintadas en color rojo.

Un caso emblemático es el Parque Nacional Kakadu, el segundo parque natural más grande del mundo y a la vez un parque cultural paradisíaco, situado en el norte de Australia y habitado por aborígenes durante más de 40 mil años. Tiene el tamaño de Israel. Las numerosas muestras de arte rupestre y su complejo conjunto de ecosistemas Ilevaron en 1981 a ser declarado Patrimonio de la Humanidad por la Unesco.

Desde hace miles de años, las pinturas rupestres de este parque vienen reflejando la estrecha relación que los primitivos pobladores de Australia tienen con la naturaleza, la tierra y su herencia espiritual. En los emplazamientos artísticos de Ubirr y Nourlangie, por ejemplo, puede encontrarse una fabulosa colección de pinturas sobre rocas, que muestran la riqueza cultural y ecológica del lugar. Las pinturas rupestres muestran escenas de caza y actividades cotidianas, así como objetos y utensilios diversos. También cuentan historias de tiempos pasados, que servían para enseñar a los más jóvenes a discernir el bien del mal, y para aprender su cultura, sus tradiciones y la historia de su pueblo. La flora del Parque Nacional de Kakadu es una de las más ricas de toda Australia.

En el Perú, hay algunos ejemplos que podríamos denominar parques culturales como sucede en Cusco. Las comunidades 
quechuas crearon el Parque Espiritual del Vilcanota en Cusco. Las comunidades quechuas de $Q^{\prime}$ eros y Ausangate, ubicadas en el Nudo de Vilcanota (Cusco, Perú), hicieron lo propio con el Parque Espiritual del Vilcanota. Se trata del establecimiento de la primera Área Natural Sagrada en el Perú, un modelo que busca el reconocimiento y promoción de los valores y principios de la cultura quechua y la conservación y uso sustentable de la biodiversidad.

La región de Vilcanota concentra el segundo sistema glaciar más importante del Perú. La cordillera está dominada por el nevado Ausangate (6 372 m), considerado como el Apu principal de los Andes del sur, donde cada año más de 50 mil personas procedentes de todas las regiones de los Andes hacen peregrinaje al nevado para participar en las fiestas del Señor de $Q^{\prime}$ oylloriti, en las que realizan rituales tradicionales que parecen recordar los honores prehispánicos ofrecidos al Apu Ausangate.

En Lima, el trabajo realizado en la Huaca Pucllana, ubicada en el distrito de Miraflores, es quizás uno de los mejores ejemplos que tenemos en el ámbito nacional. Se han realizado una serie de actividades destinadas a la conservación y puesta en valor de este centro ceremonial de la cultura Lima, que se desarrolló entre los años 200 y 700 d.C. y fue uno de los conjuntos religiosos más importantes y destacados del valle bajo del Rímac. Hoy cuenta con un Patronato, cuyo objetivo es transformar el monumento en un centro cultural de primer orden, y con un modelo de gestión privada exitosa, bajo la coordinación y supervisión del Ministerio de Cultura.

El desarrollo de las excavaciones arqueológicas es una de las principales preocupaciones y tenemos sorprendentes hallazgos y descubrimientos que permiten definir la arquitectura así como recuperar valiosa información del modo de vida de la sociedad que le dio origen.

Pucllana o "lugar de ceremonias festivas", es el nombre quechua con el que se denominaba en el siglo XVI a este centro ceremonial, edificado por la cultura Lima hacia el siglo $V$ después de Cristo.

Pucllana fue abandonada entre los siglos VII y VIII d.C. probablemente por efecto de dos factores: la llegada de una fuerte corriente religiosa traída por los Wari desde Ayacucho, que dominó la costa central aproximadamente hacia el siglo XII d.C. y por un cambio climático que generó la disminución de la producción agrícola, según información de su investigadora principal, Dra. Isabel Flores Espinoza.

Durante la época Wari, la cima de la pirámide fue usada para enterrar a sus personajes principales, pero estas tumbas fueron luego disturbadas por los Ichma (siglos XII-XIV) pobladores locales que veneraban a Pachacamac y buscaban reivindicar su cultura.

Al pasar el tiempo Pucllana se convierte en lugar de ofrendas y es venerada como una "huaca", incluso cuando los conquistadores incas llegan aquí el sitio ya era considerado un "ñaupallaqta" (pueblo viejo) de carácter sagrado, según refieren documentos coloniales.

Hoy podemos apreciar un pequeño museo de sitio, un circuito turístico donde se ven las excavaciones arqueológicas, un restaurante de primer orden, un jardín de plantas autóctonas, una pequeña granja de animales autóctonos, estands de artesanía, espectáculos culturales diversos; es decir, se ha convertido en todo un parque cultural, con una gran afluencia de visitantes, experiencia que nos puede servir de ejemplo.

El tramo del Camino Inca en Huánuco que nos interesa impulsar en esta propuesta de diseño de modelo de gestión es el que entra por Yanahuanca, pasa por Tambococha en Cauri (Tunsucancha), Jesús, Baños, Rondos, llega al Ushno de Huánuco Pampa, sube por Colpa, para finalmente llegar a Taparaco - Taparaku y de allí pasar a Ancash y La Libertad. Es decir, el tramo YanahuancaTaparaco. 
Lo que pretendemos a través de este estudio es presentar el modelo de gestión cultural a través de las experiencias de parques culturales, aprovechando los recursos arqueológicos de Huánuco, puesto que la gestión del patrimonio, en su sentido más completo, alude a la programación de todas aquellas acciones que redundan en un acercamiento del mismo a la sociedad, en una correcta administración de los medios disponibles o en el cuidado por la conservación, la investigación y la difusión para que finalmente el patrimonio revierta a la sociedad que lo creó.

\section{RESULTADOS}

Huánuco está ubicado en la parte centro oriental del Perú, bañado por los ríos Pachitea, Marañón y Huallaga. La zona de estudio abarca los valles del Vizcarra, Pachitea y parte del Alto Huallaga, en los cuales queremos ver la distribución y ubicación de los sitios arqueológicos. Priorizamos estas áreas por la necesidad de tratamiento de los sitios para su conservación y por la carencia de información que hay sobre los sitios arqueológicos en el valle de Pachitea. La superficie territorial es muy desigual, desde hoscas y violentas cumbres hasta sosegadas y bajas tierras selváticas

El camino imperial que unía el Cusco con Quito y con Chachapoyas atravesaba Huánuco, y sus ramales penetraban a las naciones de los huanucos, chaupihuarangas, yachas, chupachos, huacrachucos, panatahuas y zonas selváticas, ingresaba de sur a norte por Huarautambo (Bombón), seguía por Tambococha (Cauri), Cochapampa (Jesús), Conoc (Baños), llegando a Huánuco Pampa; proseguía por el puente de Huachanga a Huamanín (de este lugar torcía a la izquierda, en dirección al Callejón de Huaylas) (4).

La propuesta está ligada al turismo cultural y constituye una reafirmación de las propiedades de la denominada era de la posmodernidad, en la que el desarraigo del hombre contemporáneo por el fenómeno de la globalización y el imperio de lo efímero, está impulsando una búsqueda de autenticidad e identificación en el pasado y en lo cercano (5).

Es importante la implementación de parques culturales en los sitios arqueológicos que según la tipología del Ministerio de Cultura lo considera como $A 1, B 1$, etc. $Y$ no existe la denominación como tal, por lo que considerando la Ley de Aragón creemos necesario incluirlo para el Perú.

En el Perú tenemos un buen ejemplo de gestión cultural realizada por Isabel Flores Espinoza en el parque arqueológico Pucllana, el cual hoy brinda servicios a la comunidad como el restaurante turístico, el museo de sitio, los módulos de artesanías, los talleres de arqueología para niños en vacaciones escolares, y los ambientes donde incluso se narra cuentos a los niños.

Los caminos incas despertaron el interés de los primeros cronistas españoles que llegaron al implantarse la Colonia. Los escritos de Francisco de Jerez y Pedro Sancho, así como el veedor Miguel de Estete, se encuentran plagadas de notas sobre la red de caminos incaicos; en ellas encontramos ideas sobre la forma de construcción, emplazamientos de tambos y pueblos, locación de puentes, etc. También investigadores y viajeros como Squier, Markham, Raymondi, Von Hagen y Alberto Regal, se interesaron por la grandeza del camino, describiéndolo y registrándolo en su momento de visita Sin embargo, será John Hyslop quien investigara el Sistema Vial Inca dándole un enfoque analítico al realizar los primeros recorridos sistemáticos, identificando los sitios y sus rasgos asociados (6).

Qhapaq Ñan, el camino principal andino, fue concebido como el elemento unificador y la base del sustento de la compleja estructura organizativa inca. Sin este elemento no hubiera sido posible que la sociedad inca alcanzara uno de los desarrollos sociales más complejos de América, en un lapso de tiempo tan corto, integrando un territorio geográficamente adverso con una diversidad cultural marcada por etnias 


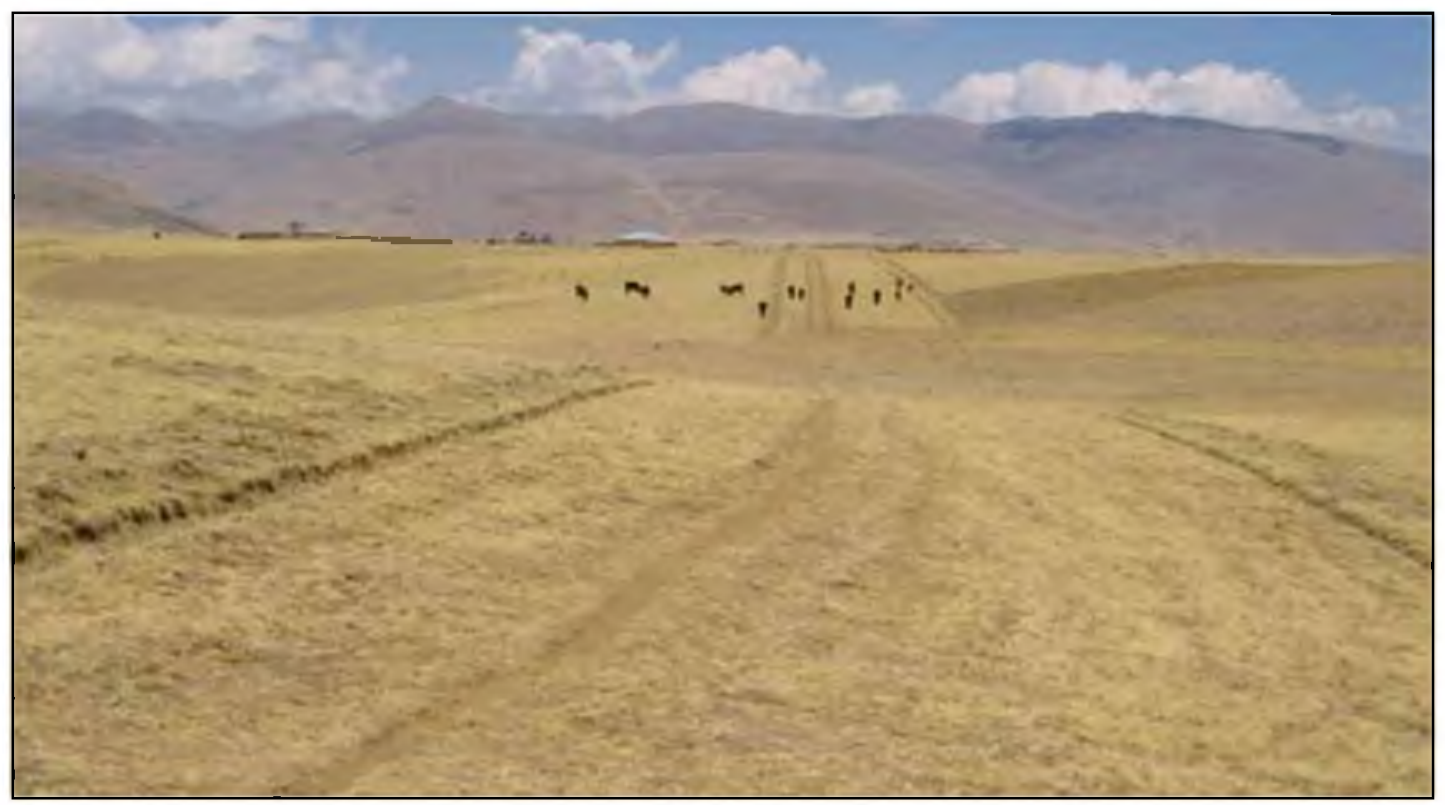

Figura $N^{\circ}$ 1: Ruta del Camino Inca que ingresa a Huánuco Pampa (mide hasta 15 metros de ancho).

establecidas en todo el territorio peruano y sudamericano. El Qhapaq N̄an, además, fue el corolario de numerosos procesos de desarrollo de planificación y construcción realizados por diversas culturas anteriores a los incas (4).

El Qhapaq Nan no solo es importante por su magnitud -es el monumento de mayor dimensión de América-, sino por la capacidad de unir las diferentes regiones que formaban el Tahuantinsuyo. Ello implicó unir sus recursos naturales, sus economías, sus poblaciones, sus culturas; el Tahuantinsuyo ejerció el control de estos lugares mediante la infraestructura vial que las conecta y enlaza (6).

Consideramos como aporte el parque cultural, cuya nomenclatura no es usada en nuestro país para un modelo de gestión cultural, y tomamos como ejemplo el patrimonio cultural de Huánuco, dirigido tanto al turismo interno como al receptivo,

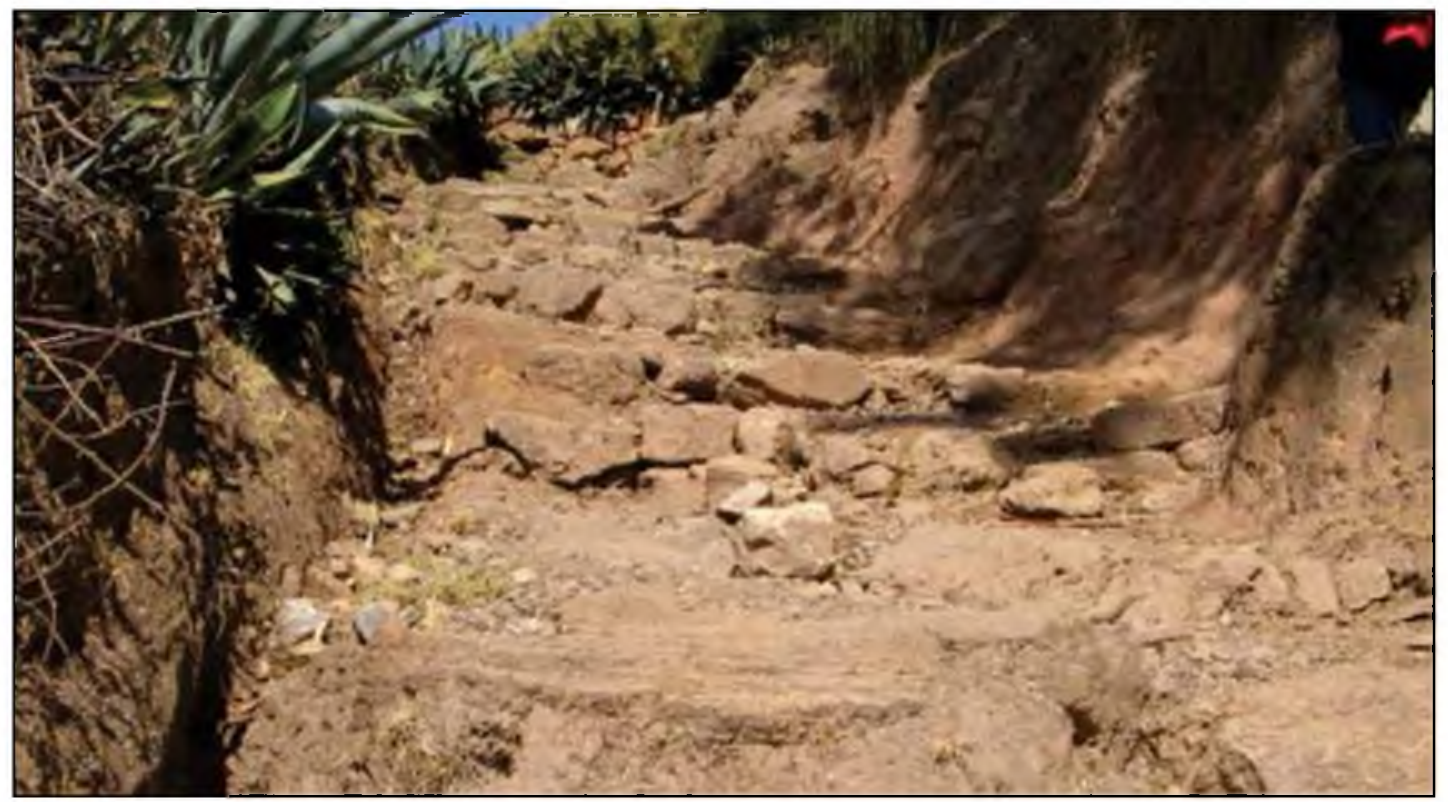

Figura $\mathrm{N}^{\circ}$ 2: Ruta de las escalinatas del Camino Inca en Shunqui. 


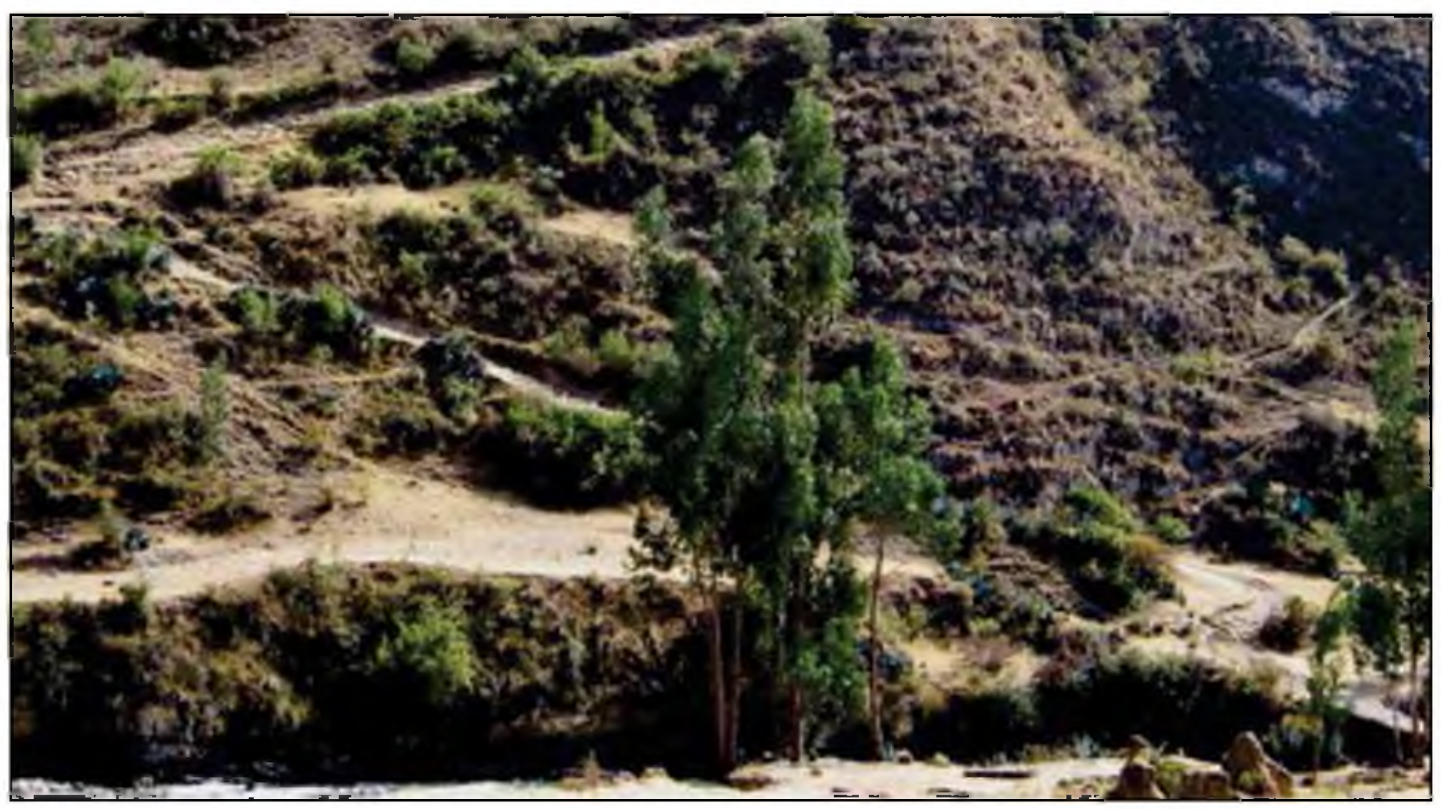

Figura $N^{\circ}$ 3: Ruta del Camino Inca en Dos de Mayo, cerca de Pachas.

para un mejor aprovechamiento de los recursos tanto culturales como naturales del territorio peruano y especialmente del huanuqueño, en el tramo que corresponde al Camino Inca (figuras 1, 2, 3).

Este modelo de gestión cultural corroboraría no solo a salvaguardar este patrimonio, sino optimizar su aprovechamiento $y$ hacer de Huánuco un destino turístico, que esperamos tenga eco en los gobiernos locales y en el Gobierno Regional, puesto la propuesta que este parque cultural involucra desde el tambo de Tunsucancha - Tambococha (provincia de Lauricocha) hasta el tambo de Taparaco (Huamalíes), pasando por la provincia de Dos de Mayo; es decir, abarcaría 68,34 km (figura 4), y donde no solo se considera la magnífica obra construida del Camino Inca (figura 5), sino también los sitios arqueológicos próximos, las poblaciones aledañas, el paisaje de lagunas, nevados, bosques de piedra, planicies, etc.

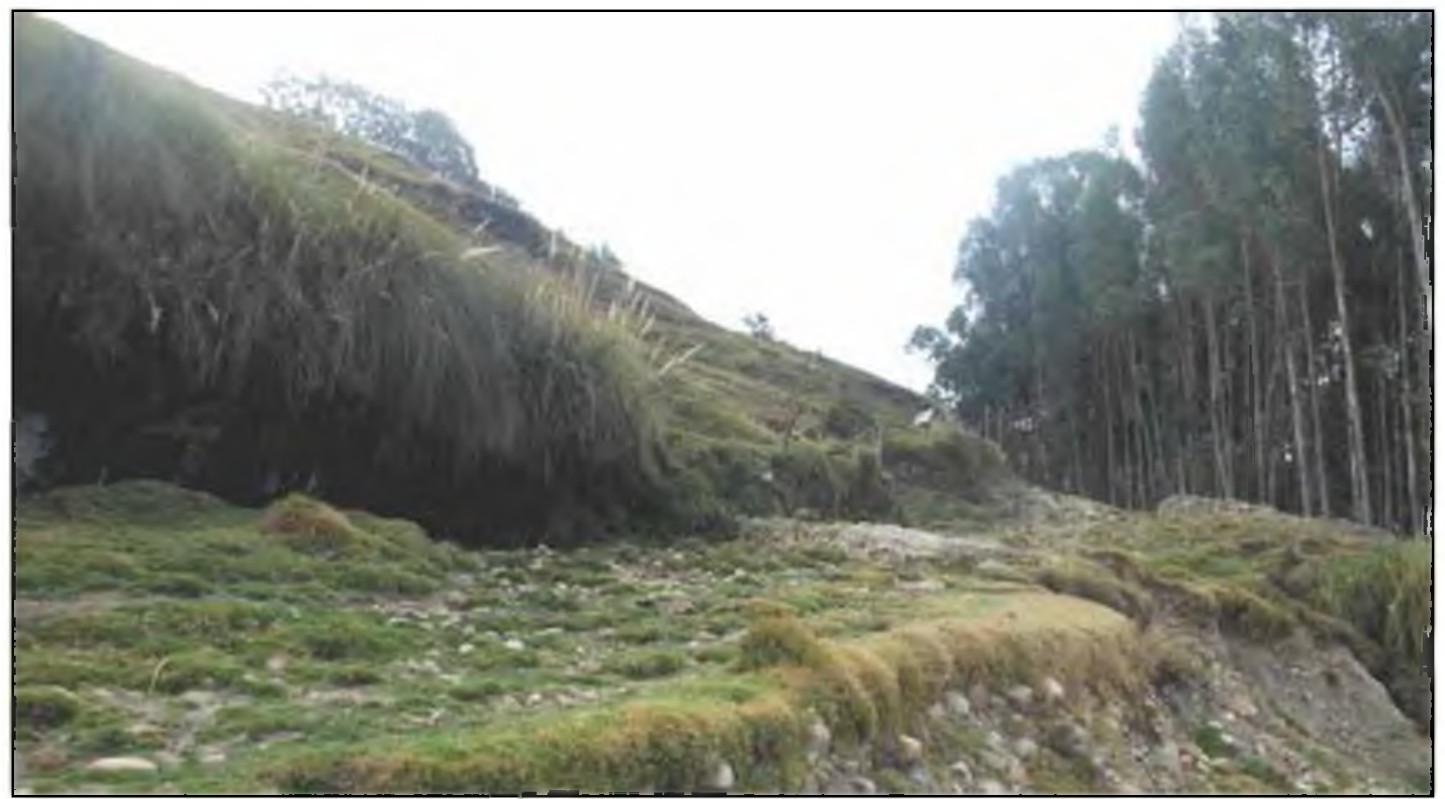

Figura $\mathrm{N}^{\circ}$ 4: Ruta del Camino Incaico hacia los Baños del Inca en la zona de Calientes. 


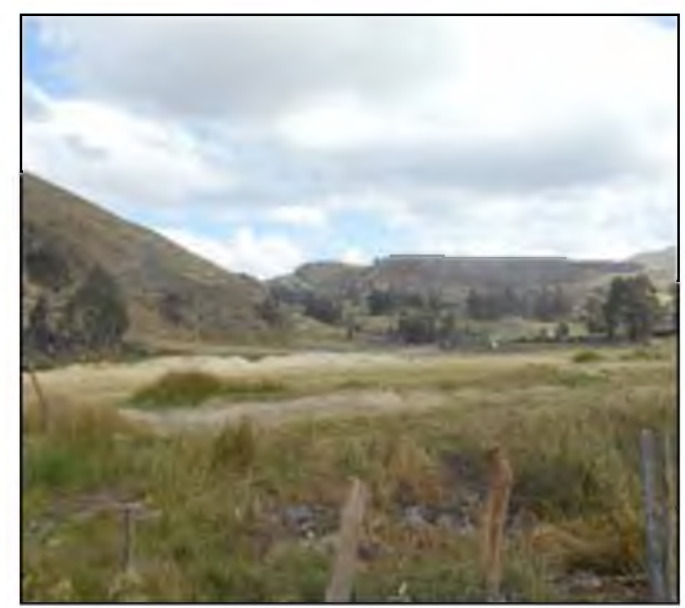

a) Ruta del Camino Incaico hacia Rondos próximo a los Baños del Inca.

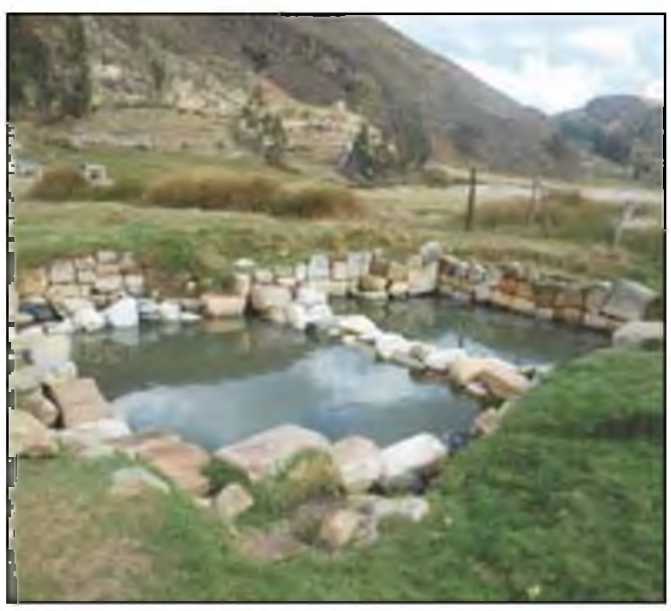

b) Los Baños del Inca en Calientes.

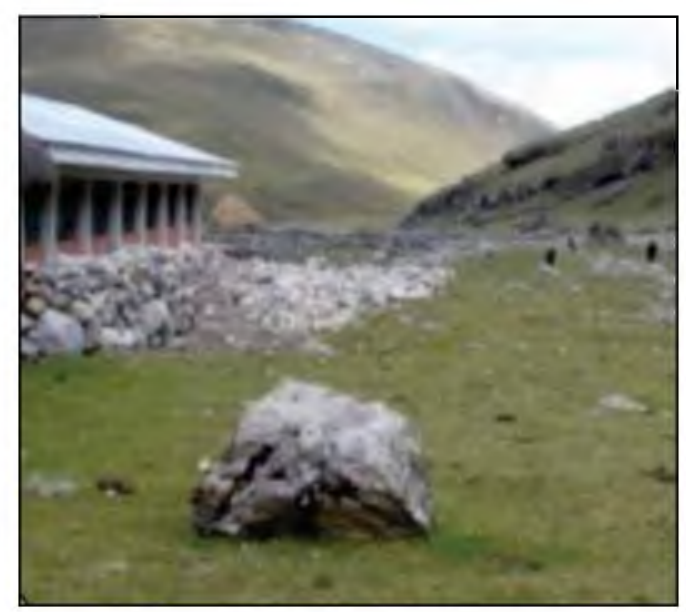

c) El tambo de Taparako.

Figura $\mathrm{N}^{\circ}$ 5: Parte de la obra construida en el amplio trayecto del Camino Inca en Huánuco.

Además, Huánuco estaría contribuyendo a que Qhapaq Ñan sea considerado Patrimonio Cultural de la Humanidad, por ser este uno de los tramos mejor conservados del Camino Inca, actualmente está muy expuesto y sin ninguna medida de defensa y conservación con el peligro de desaparecer por una falta de política cultural y una inadecuada gestión cultural.

\section{DISCUSIÓN}

Postulamos a Qhapaq Nan como parque cultural, por la complejidad y riqueza de los recursos tanto culturales como naturales en Huánuco; es decir, cuenta con patrimonio cultural arqueológico en buen estado de conservación la pesar de no haber sido atendido) como es el Puente Inca de Lauricocha, los Baños del Inca en Calientes (actualmente en uso), la ciudad de Huánuco Pampa, y tramos del camino en buen estado, así como otras construcciones y edificaciones incas y preincas próximas a este medio vial. También lo hacemos por su atractivo natural, por su ruta es posible ver aún la cordillera Blanca, lagunas, nevados y paisaje, así como poblaciones propias de zonas altoandinas, con sus costumbres y folclore. Conjugando todo ello constituirían atractivos de primer orden, que será impulsado mucho más con la investigación y el tratamiento adecuado que demanda un parque cultural.

El Qhapaq Ñan puede constituirse en el referente para las futuras comunicaciones 
andinas, superando la organización de las actuales, gracias a su papel integrador. E inclusive serviría para potenciar el deporte y a la vez promover la imagen turística de esta zona, a través de la organización de concursos de chasquis por este camino y otras actividades estratégicas de esparcimiento y promoción.

Es por ello que proponemos que este tramo del Camino Inca, que corresponde a la región de Huánuco, sea considerado parque cultural, cuyos objetivos son similares a los considerados en la Ley Aragón (1997) y de acuerdo con las directrices prácticas para la aplicación de la Convención del Patrimonio Mundial, del 2 de febrero del 2005 (5).

\section{REFERENCIAS BIBLIOGRÁFICAS}

1. Fundación del Patrimonio Histórico de Castilla y León. Turismo Cultural: El patrimonio histórico como fuente de riqueza. Valladolid, España: Fundación del Patrimonio Histórico de Castilla y León; 2000.

2. Fundación del Patrimonio Histórico de Castilla y León. La gestión del patrimonio cultural. La transmisión de un legado, actas del simposio internacional La Gestión del Patrimonio Cultural. Valladolid, España: Fundación del Patrimonio Histórico de Castilla y León; 2002.

3. Varallanos J. Historia de Huánuco. Buenos Aires: López; 1959.

4. Hyslop J, Guerrero B, Lumbreras L. El Camino Inka entre el río Yanahuanca y la Ciudad Inka de Huánuco Pampa: departamentos de Pasco y Huánuco, Perú. Gaceta Arqueológica Andina. Instituto Andino de Estudios Arqueológicos, Lima. 1992; 6(21).

5. Tello S. Patrimonio: Turismo y Comunidad. Turismo y Patrimonio. Escuela Profesional de Turismo y Hotelería de la Universidad San Martín de Porres, Lima. 2000: 1(1).

6. Hyslop J. El sistema vial incaico.
Lima: Instituto Andino de Estudios Arqueológicos; 1992. 